\title{
Streamlining the Processes Preceding an Operation Using Six Sigma
}

\author{
Ankit Singh, ${ }^{1 *}$ Sougrakpam Sushillo Singh ${ }^{2}$ and Priya Ravi ${ }^{3}$ \\ ${ }^{1}$ Department of Hospital Administration, Sikkim Manipal University, Gangtok-737101, India \\ ${ }^{2}$ Department of Hospital Administration, Jivan Hospital Kakching, Manipur-795001, India \\ ${ }^{3}$ Department of Hospital Operations, Central Referral Hospital, Gangtok-737101, India
}

"Email: anktsngh15@gmail.com

ARTICLE INFORMATION

Received: June 16, 2018

Revised: July 04, 2018

Accepted: July 18, 2018

Published online: August 6, 2018

Keywords:

Six Sigma, Operation Theatre Utilization, Pareto analysis, Cause and Effect Diagram

\begin{abstract}
Purpose: The operation theatre is the major cost and revenue centre in a hospital. The operation theatre's optimum utilization will not only increase the revenue for the hospital but will also have a significant positive impact on customer satisfaction, for both internal and external customers. The present study aims in improving the existing process in an operation theatre suite of a tertiary care private hospital in Siliguri (West Bengal), which suffers from a process related problem, delay in scheduling operations (Sigma level 2.17), as found out in the Pilot Study. The study is carried out to improve the sigma level. Aligning with it, the operation theatre utilization is calculated with the objective of its bench marking, as per industry standards.

Design/Methodology/Approach: The study is conducted within the framework of Defining, Measuring, Analysing, Improving, and Controlling (DMAIC) method of Six Sigma. To begin with, the Pilot Study is carried out to identify and define the problem. At the measuring and analysing stage, Pareto analysis technique is employed, aided by the Cause and Effect diagram. After the identification, causes are categorised as controllable and uncontrollable. This is followed by a brainstorming session, which is conducted in order to work out solutions relating to controllable causes. The Time Motion study data of 192 surgery cases is collected for the pre-implementation phase, while that of 236 surgery cases is collected for the post-implementation phase. An independent $t$ test is carried out to find out the difference in the outcomes, both in the pre-implementation and the post-implementation phases, thereby reflecting the effectiveness of the solutions implemented.

Findings: The baseline sigma level of 2.17 is improved to reach the 3.0 sigma level, concerning delay of scheduled operations. This is achieved by reducing the time lag that is experienced when shifting the patient from the Ward to the Operation Theatre, as also that relating to the cleaning and setting up of the Operation Theatre, between two surgeries.

Practical implications: Reducing the set up and the cleaning time between two procedures helps in reducing the delay in scheduled operations, which can be achieved by the practice of shifting the patient one hour prior to the scheduled surgery. Similarly, when more surgeries need to be performed, their turnaround time can be reduced by deploying an adequate number of housekeeping staff. Thus, more number of surgeries can be done in a day and operation theatre utilization can be optimised.
\end{abstract}

(Chowduhry, 2002) and business strategy (Antony \& Banuelas, 2002). The Six Sigma methodology is used in several departments of a hospital, such as the outpatient department (Gijo \& Antony, 2014), discharge process (ElEid, Kaddoum, Tamim, \& Hitti, 2015), admission process (Tolga Taner, Sezen, \& Antony, 2007), medication process (Chassin, 2009), diagnostic imaging (Tolga Taner, Sezen, \& Atwat, 2012) and operation theatres (Singh, Remya, Shijo, \& Nair, 2014). However, there are not enough studies which have tried to solve the operation theatre delay problem with the Six Sigma approach. The operation theatre is one among the major revenue producing departments in 
a hospital (Siddharth, Kumar, Vij, \& Gupta, 2015). It is both labour intensive and cost intensive, as it requires a huge investment and a large team of professionals, consisting of surgeons, anaesthetists, operation theatre technicians, operation theatre assistants, operation theatre nurses, and so on. Good investments are required for installations of fixtures and equipment, and meeting design parameters, so as to ensure strict aseptic conditions. On an average, an operation theatre follows an eight-hour work schedule, per operating room, excluding emergency cases. In that eight hour work schedule, at the most, four major operations can be carried out, and if an optimal mix of operations is done, this can reach up to five-six operations per day .However, the operations department in most hospitals struggle with the problem relating to operation theatre's optimum utilization, caused by system inefficiencies and human errors; there are delays and wastes, which act as bottlenecks for optimum utilization of operating rooms (Vinukondaiah, Ananthakrishnan, \& Ravishankar, 2000).

Jawaharlal Institute of Postgraduate Medical Education and Research, Pondicherry. Operation theatre utilization was studied with respect to the starting and closing of the operation theatre, interval between surgical procedures, cancellation of surgical procedures and reasons thereof. RESULTS: The operation theatre was functional for 279 days during the year of the study, and 1773 cases were operated (6.3 cases per day. The hospital, in question, also suffers from delay in scheduling operations as found out in interaction with operation theatre staff, which resulted in underutilization. Hence, this study is carried out with the following objectives:

1. To measure utilization of the operation theatre department

2. To identify the reasons for the delay when carrying out operations, and to improve the process by reducing them with Defining, Measuring, Analysing, Improving and Controlling (DMAIC) method.

\section{Methods}

Initially a pilot study was carried out in this 250 bed super speciality tertiary care hospital, situated in Siliguri city, of West Bengal state, in India. The operation theatre department in this hospital is on the third floor, between CSSD (Central Sterile Supply Department) and Catheterization Laboratory, as per the functional relationship. There are four major modular uniformlysized operation theatres (400 sq. $\mathrm{ft}$.). The study design is prospective, cross sectional and interventional, the scope of the study includes all the surgical cases that are performed in the three multiple-use operating rooms in the eight hour shift, i.e., from 8:30 A.M to 4:30 P.M. Data collected is primary in nature, collected through direct observations, with the help of time-tracking sheet. In the process, the start event is the shifting of the patient from the Ward/ the ICU (Intensive Care unit) and the end event is the shifting of the patient from the Operation Theatre recovery room to the respective Ward/ the ICU. The software used for data analysis is SPSS (Statistical Package for Social Sciences) version 20 and Minitab version 16. Operation Theatre Utilization is calculated with the formula (Hartmann \& Sunjka, 2013): Utilization $=($ Time used) divided by (Time Available), i.e., it is the quotient of hours of operation theatre time actually used during elective resource hours and the actual number of elective resource hours available for use. There are three functional operation theatres in the period from March to April 2017: Operation Theatre -1, Operation Theatre- 2 and Operation Theatre -3

Table 1: Operation Room utilization in the Pre-implementation phase.

\begin{tabular}{|c|c|c|}
\hline $\begin{array}{c}\text { Sl. } \\
\text { no }\end{array}$ & Operation Theatre & Utilization Quotient \\
\hline 1 & Operation Theatre-1 & $67.25 \%$ \\
\hline 2 & Operation Theatre-2 & $52 \%$ \\
\hline 3 & Operation Theatre- 3 & $85 \%$ \\
\hline
\end{tabular}

Table 2: Percentage of types of surgeries carried out in the hospital.

\begin{tabular}{|l|c|}
\hline Speciality & Percentage \\
\hline Gynaecology & 29.98 \\
\hline Urology Surgery & 20.37 \\
\hline ENT (Ear, Nose, Throat) Surgery & 14.05 \\
\hline General Surgery & 13.35 \\
\hline Ortho Surgery & 7.03 \\
\hline Plastic Surgery & 6.79 \\
\hline Paediatric Surgery & 4.22 \\
\hline Neuro Surgery & 3.98 \\
\hline Dental Surgery & 0.23 \\
\hline
\end{tabular}

The average time utilization for Operation Theatre -one, Operation Theatre -two, and Operation Theatre -three is 5:38 hours, 4:24 hours and 8:47 hours respectively. The composite utilization of the three operating rooms was found to be $68.08 \%$, lower than the global benchmark of $80 \%$ operating room utilization (B.M. Sakharkar, 2008). The total number of operations performed during the duration of study is 428 elective schedule cases. The preimplementation stage consisted of 192 cases and the postimplementation one consisted of 236 cases. Gynaecology, Urology and ENT (Ear, Nose and Throat) surgeries 
accounted for $64.4 \%$ of all the surgeries carried out in the hospital.

\section{Defining Phase}

In the Defining Phase, the Pilot Study is performed, and the problem is defined as that in which Surgeons (Internal Customers) are dissatisfied with the prevailing percentage of delay in scheduled operations, which is $25.13 \%$, at 2.17 Sigma level. The study's goal is to improve the Sigma level to 3.0 in the first phase. The metrics developed for this study is delay percentage. A project charter is developed, which includes problem description and objectives, along with the primary metric of the percentage of delay in scheduled operations. The operational definition of delay was any operation getting delayed by more than 10 minutes from the scheduled time in accordance with AAGBI (The Association of Anaesthetists of Great Britain and Ireland) (Ciechanowicz \& Wilson, 2010). Split over two sites. Information was collected onto a proforma for each case about specialty, procedure, start-time and end-time of the case, with request for an explanation for duration and reason for any delays incurred. An analysis of costs to the Trust was performed using estimated theatre hours lost with average cost of theatre use per hour. Overall $78 \%$ of cases started on time, i.e. within 15 minutes of the scheduled time, but orthopaedics and plastics achieved only $69 \%$ and $66 \%$ respectively. Orthopaedics and plastics also exceed the acceptable total daily delay time of 45 minutes (70 and 66 minutes respectively. The team for this study comprises the process owner and key stakeholders, as well as the personnel who have attained the Six Sigma Green Belt level.

\section{Measuring Phase}

In the pre-implementation phase, the average time taken for shifting the patient from the Ward to the Induction room is ten minutes, the average time taken from the Anaesthesia to the Incision is 11 minutes, the average duration of closing to the Anaesthesia during reversal is four minutes, the average duration of reversal of the patient out from Operation Theatre is ten minutes, and the average cleaning and setting up duration for the next case is 14 minutes. In the Measure Phase, critical ' $Y$ ' determined is in reducing the number of delays.

Pareto analysis is done for finding out important delay reasons (Figure 1) in the Defining Phase and it is found that delay in shifting the patient from the Ward, the previous surgery's time extension and the surgeon's late arrival constitute nearly $71 \%$ of overall delays. Hence, these three factors are considered as the key independent variables, which are denoted as ' $\mathrm{X}$ '. With the objective to reduce the 'Xs', a detailed process map is developed. In the later part of this phase, a data collection plan (DCP) is developed, following team members brainstorming session.

Table 3: Reasons for delay in carrying out operation.

\begin{tabular}{|l|l|l|l|}
\hline $\begin{array}{l}\text { Sl. } \\
\text { No }\end{array}$ & Reasons & Count (48) & Percentage \\
\hline 1 & Delayed shifting from ward & 16 & 34 \\
\hline 2 & $\begin{array}{l}\text { Extension of previous } \\
\text { surgery }\end{array}$ & 9 & 19 \\
\hline 3 & Late arrival of surgeon & 9 & 19 \\
\hline 4 & Delay in financial clearance & 5 & 11 \\
\hline 5 & $\begin{array}{l}\text { Delay in making available } \\
\text { investigation reports }\end{array}$ & 3 & 7 \\
\hline 6 & Emergency case & 2 & 5 \\
\hline 7 & Unplanned admission & 2 & 5 \\
\hline 8 & $\begin{array}{l}\text { Delay in anaesthetic } \\
\text { clearance }\end{array}$ & 1 & 3 \\
\hline 9 & $\begin{array}{l}\text { Unavailability of patient } \\
\text { relative }\end{array}$ & 1 & 3 \\
\hline & Total & 48 & 100 \\
\hline
\end{tabular}

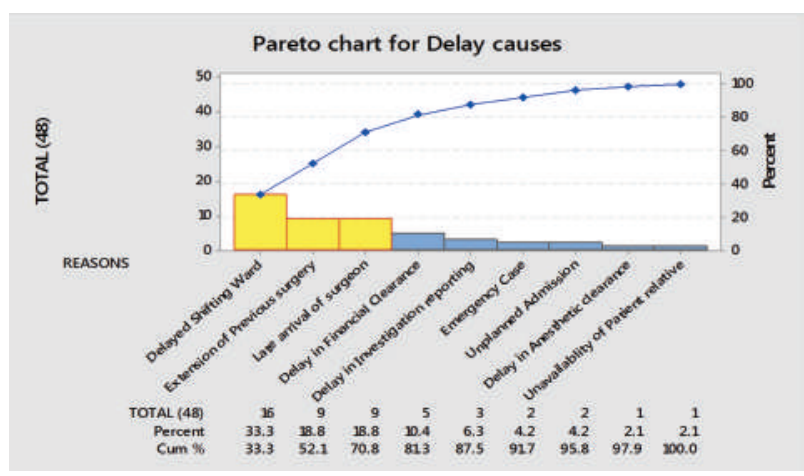

Figure 1: Pareto Chart for causes of delay.

\section{Analysing Phase}

In the Analysing Phase, thorough data analyses are done to identify the causes behind delays in the scheduling of operations. A brainstorming session is carried out with the Operating Room staff members and other stakeholders of the process. As its fallout, Cause and Effect diagram (Figure 2) is prepared. Causes behind delays, identified with the help of Cause and Effect diagram, are classified into controllable and non-controllable ones. Non-controllable causes relate to the extension of previous surgeries and emergency cases. Another brainstorming session is carried out to discuss solutions for controllable causes behind delays (Table IV). 


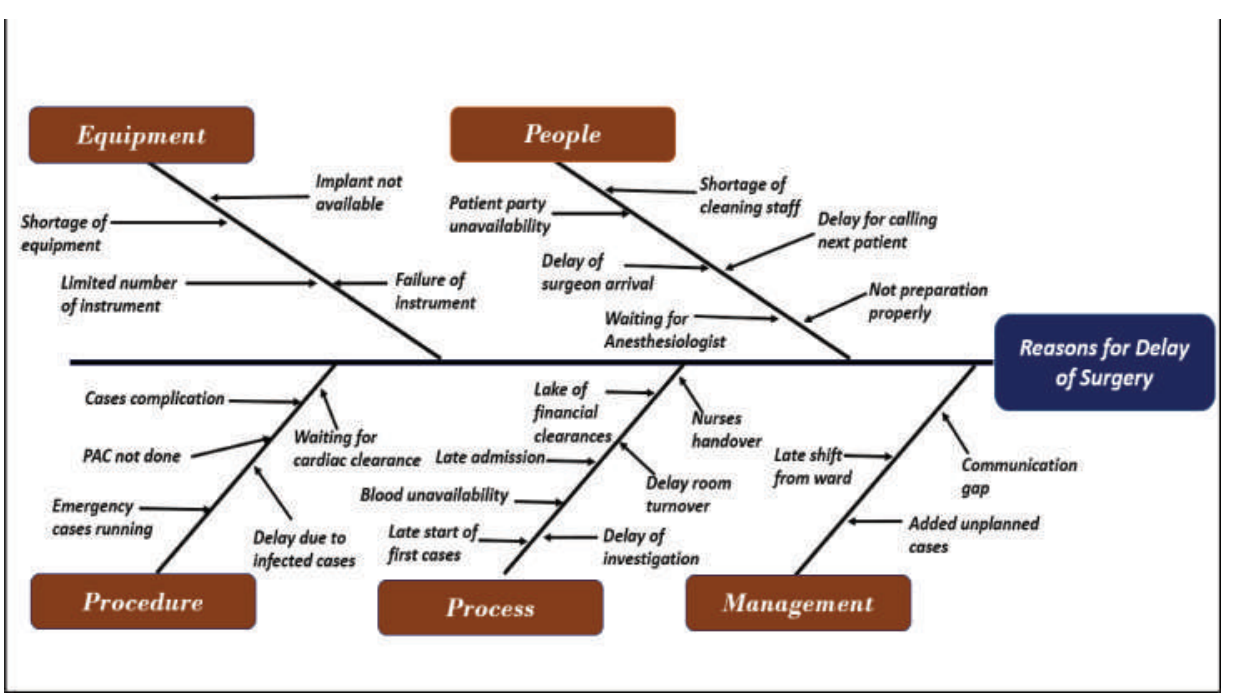

Figure 2: Cause and Effect Diagram of reasons of delay.

Table 4: Solutions for controllable causes of delay in carrying out the operation.

\begin{tabular}{|l|l|}
\hline Reasons & Solutions \\
\hline Extension of previous surgery & Non controllable factor \\
\hline Emergency Case & Non controllable factor \\
\hline Same day admission for surgery & $\begin{array}{l}\text { Policy formulation to not allow same day surgery for elective cases, and strict adherence } \\
\text { to OT schedule excluding emergency cases. }\end{array}$ \\
\hline Late Financial Clearance & $\begin{array}{l}\text { Policy formulation to enhance Coordination between doctor and Billing (estimation) } \\
\text { Clerk. }\end{array}$ \\
\hline Late Shift From Ward & $\begin{array}{l}\text { Increases number of General Duty assistants, Policy formulation of ensuring patient } \\
\text { shifting 1 hour prior to the scheduled surgery time by ward coordinators. }\end{array}$ \\
\hline Unavailability of Patient relatives & $\begin{array}{l}\text { At the time of admission minimum two relatives contact number will be taken and at } \\
\text { the time of counselling scheduled time for surgery will be clearly stated }\end{array}$ \\
\hline Delay in Anaesthetic clearance & $\begin{array}{l}\text { Copy of OT schedule will be sent to anaesthetics and regular follow up will be taken by } \\
\text { ward nurses if Anaesthetic clearance is not done or delayed. Indicator will be maintained } \\
\text { for the delay in Anaesthetic clearance and will be intimated to the Anaesthesia HOD on } \\
\text { timely basis to work upon it to reduce it. }\end{array}$ \\
\hline $\begin{array}{l}\text { Waiting For Investigation Report } \\
\text { between two procedures }\end{array}$ & $\begin{array}{l}\text { All reports and investigations will be checked one day prior and will be cross checked by } \\
\text { the nurse. }\end{array}$ \\
\hline $\begin{array}{l}\text { Reminder for the surgery timings will be sent one day prior and morning SMS will also } \\
\text { be sent. }\end{array}$ \\
$\begin{array}{l}\text { Increasing Housekeeping staff and Sensitizing them about the importance of work } \\
\text { performed by them. }\end{array}$ \\
\hline
\end{tabular}

\section{Improving Phase}

In the Improving Phase, solutions are implemented, and an independent $t$ test is conducted to compare the Ward-to-Operation-Theatre shifting times, before and after the implementation of solutions. There is significant difference seen in the before and after shifting times, for Pre-implementation $(\mathrm{M}=0.11$, S.D $=0.06)$, and Postimplementation $(\mathrm{M}=0.07$, S.D $=0.03$; $\mathrm{t}(425)=7.009$, $\mathrm{p}$
$=0.00$, two tailed). The magnitude of the difference in the means (mean difference $=0.03,95 \% \mathrm{CI}: 0.02$ to 0.04 ) is medium size, with $r=0.32$. Moreover, while comparing the set up time of Post-implementation $(\mathrm{M}=0.11, \mathrm{~S} . \mathrm{D}=0.03)$ and Pre-implementation $(\mathrm{M}=0.14$, S.D $=0.05$; $\mathrm{t}(425)=$ $6.65, p=0.00$, two tailed), statistically significant difference is found. However, the magnitude of the difference in the means (mean difference $=0.02,95 \% \mathrm{CI}: 0.02$ to 0.3 ) is of 
medium effect, with $r=0.30$ The Pre-implementation and Post-implementation means relating to the patient shifting time from the Ward to the Operation Theatre, as also those relating to Set up and cleaning time comparisons, are shown by the Box plot (Figure 3).

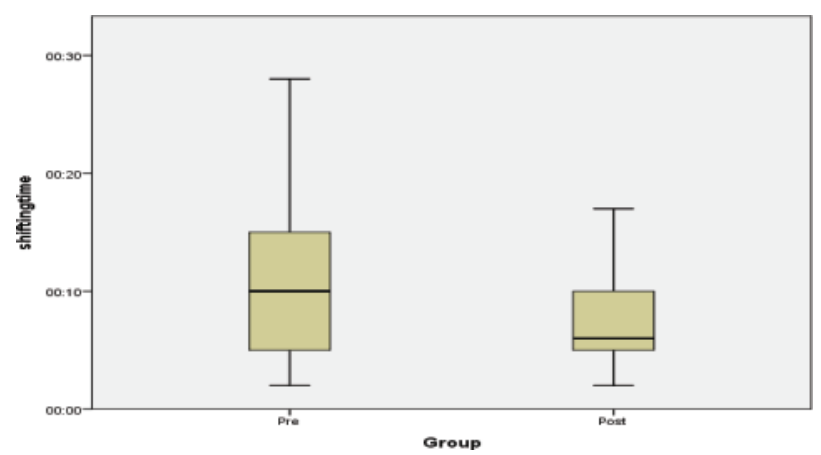

Figure 3: Box plot relating to patient- shifting time from the Ward to Operating Room (Pre-utilization and Post-utilization).

Table 5: Pre-implementation and Post-implementation Sigma Level comparison.

\begin{tabular}{|l|c|c|c|c|}
\hline & $\begin{array}{c}\text { Defects } \\
\text { (D) }\end{array}$ & $\begin{array}{c}\text { Unit } \\
\text { (U) }\end{array}$ & DPMO & $\begin{array}{c}\text { Six Sigma } \\
\text { Level }\end{array}$ \\
\hline $\begin{array}{l}\text { Pre- } \\
\text { Implementation }\end{array}$ & 48 & 191 & 251,308 & 2.17 \\
\hline $\begin{array}{l}\text { Post- } \\
\text { Implementation }\end{array}$ & 16 & 236 & 67,796 & 3.00 \\
\hline
\end{tabular}

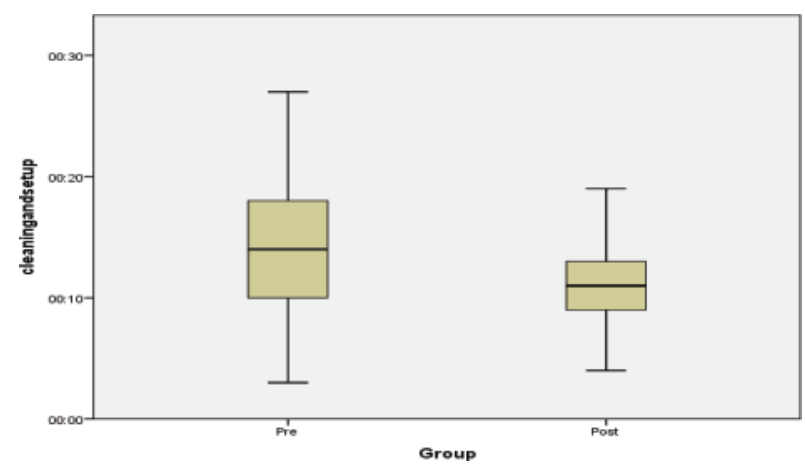

Figure 4: Box Plot relating to the Operation Theatre set up and the cleaning time between two surgical procedures (Pre-utilization and Post-utilization).

At the same time, the Pre-implementation and PostImplementation Sigma levels are compared to see the difference.

\section{Controlling Phase}

Controlling Phase: work assignments are made clear and the responsibilities for the same are given with adequate authority to Quality Personnel, Ward and Operation Theatre staff, in order to ensure strict adherence to the policy and enable continuous monitoring.

\section{Discussion}

The study's main findings are that all the three operations theatre's utilization, on an average, is $68.08 \%$, which is lower than the $80 \%$ utilization global benchmark. However, the percentage utilization shown above does not give the real picture, as this utilization time comprises that relating to non-value adding activities, such as the time taken to shift the patient from the Ward to the Operation Theatre, and the set-up time required between two procedures, which are also the procedure's major delay causes. This study emphasizes how the Six Sigma methodology can be used to reduce delays by reducing these non-values adding activities. The results of this study are in congruence to earlier works for example, In a previous study (Talati, Gupta, Kumar, Malhotra, \& Jain, 2015),It is found that the patient-shifting time from the Ward to the Operating room is the major cause of delay which agrees with this study findings. Similarly, in another study it was found that $72 \%$ of delay causes were due to hospital wide factors including delay in shifting of patients (Ciechanowicz \& Wilson, 2010). Split over two sites. Information was collected onto a proforma for each case about specialty, procedure, start-time and end-time of the case, with request for an explanation for duration and reason for any delays incurred. An analysis of costs to the Trust was performed using estimated theatre hours lost with average cost of theatre use per hour. Overall $78 \%$ of cases started on time, i.e. within 15 minutes of the scheduled time, but orthopaedics and plastics achieved only $69 \%$ and $66 \%$ respectively. Orthopaedics and plastics also exceed the acceptable total daily delay time of 45 minutes (70 and 66 minutes respectively. Similarly, the percentage of delay cases because of late arrival of surgeons in this study is 19 $\%$ which is nearly same to $20 \%$ found in another study (Kumar, Malhotra, Singla, \& Bhatia, 2016). The patientshifting time delay can be effectively managed by shifting the patient one hour prior to the scheduled surgery's time, to be made as a standard practice. The set-up time of operating room, in between two surgical procedures, also known as the operation theatre turnover (Kodali, Kim, Bleday, Flanagan, \& Urman, 2014). Sometimes through the employment of a process improvement framework. However, most examples of process improvement in the TOT focus primarily on operational changes to workflows and statistical significance. These examples of process improvement do not detail the complex organizational challenges associated with implementing, expanding, 
and sustaining change. Methods TOT data for general and gastrointestinal surgery were collected retrospectively over a 26-mo period at a large multispecialty academic institution. We calculated mean and median TOTs. TOTs were excluded if the sequence of cases was changed or cases were canceled. Data were retrieved from the perioperative nursing data entry system. Results Using performance improvement strategies, we determined how various events and organizational factors created an environment that was receptive to change. This ultimately led to a sustained decrease in the OR TOT both in the general and gastrointestinal surgery ORs that were the focus of the study ( $44.8 \mathrm{~min}$ versus $48.6 \mathrm{~min} ; \mathrm{P}<0.0001$ can be reduced by deploying adequate housekeeping staff, and sensitizing them about the importance of tasks performed by them.

\section{Conclusion}

The Six Sigma methodology is a promising one to address problems concerning operation theatre efficiency. The study also establishes that support service departments, such as the housekeeping department, can play a vital role in improving the Operation Theatre utilization. Hence, adequate consideration should be given for goal-oriented policies and manpower assessment of the Operation Theatre department. Further, coordination between all the healthcare team members has prime importance for the departments optimal functioning. In this case study, it is found that if the patient from the Ward can be shifted one hour to the Operation Theatre prior to the commencement of the operation, it will reduce the delay in scheduling operations and for this, adequate beds should be there as pre-operative beds; coordination and communication between the Operation Theatre's nurses and the Ward's nurses should be strong and smooth. Similarly, smooth coordination between nurses in wards and the housekeeping staff, who are responsible for shifting the patient from the Ward to the Operation Theatre, is also very important.

\section{Limitations}

It is the first attempt in applying the Six Sigma methodology in this hospital setting. This hospital has not been accredited when the study is carried out. Hence, staff sensitivity as to why quality is important, and the price paid for its lacking is absent. The sigma level improvement is not a breakthrough improvement, as it is improved from the 2.17 sigma level to the 3 sigma level only. However, quality is not an end in itself; it is an attribute. Hence, there is scope for improvement in the future.

\section{References}

Antony, J., \& Banuelas, R. (2002). Key ingredients for the effective implementation of Six Sigma program. Measuring Business Excellence, 6(4), 20-27. http://doi.org/10.1108/13683040210451679

B. M. Sakharkar. (2008). Principles of Hospital Administration and Planning (Second Edi). Jaypee Brothers Medical Pub.

Chassin, R. (2009). The Six Sigma Initiative at Mount Sinai Medical Center. The Mount Sinai Journal of Medicine, New York, 76(2), 173-181. http://doi.org/10.1002/MSJ

Chowduhry, S. (2002). Design for Six Sigma (First Edit). Kaplan Business.

Ciechanowicz, S., \& Wilson, N. (2010). Delays to Operating Theatre Lists: Observations from a UK Centre. The Internet Journal of Health, 13(1), 1-5.

El-Eid, G. R., Kaddoum, R., Tamim, H., \& Hitti, E. A. (2015). Improving Hospital Discharge Time. Medicine, 94(12), e633. http://doi.org/10.1097/MD.0000000000000633

Gijo, E. V., \& Antony, J. (2014). Reducing patient waiting time in outpatient department using lean six sigmamethodology. Quality and Reliability Engineering International, 30(8), 1481-1491.

http://doi.org/10.1002/qre.1552

Hartmann, D., \& Sunjka, B. (2013). Private theatre utilisation in South Africa: A case study. South African Medical Journal, 103(5), 285-287.

http://doi.org/10.7196/SAMJ.6460

Kodali, B. S., Kim, D., Bleday, R., Flanagan, H., \& Urman, R. D. (2014). ScienceDirect Successful strategies for the reduction of operating room turnover times in a tertiary care academic medical center. Journal of Surgical Research, 187(2), 403-411.

http://doi.org/10.1016/j.jss.2013.11.1081

Kumar, M., Malhotra, S., Singla, V., \& Bhatia, K. (2016). Analysis of Start Time Delay in Operation Theatre Lists. Scholars Journal of Applied Medical Sciences, 4(5), 1764-1769. Retrieved from www.saspublisher.com

Linderman, K., Schroeder, R. G., Zaheer, S., \& Choo, A. S. (2003). Six Sigma : a goal-theoretic perspective. Journal of Operations Management, 21(2), 193-203. http://doi.org/10.1016/j.jss.2013.11.1081

Siddharth, V., Kumar, S., Vij, A., \& Gupta, S. K. (2015). Cost Analysis of Operation Theatre Services at an Apex Tertiary Care Trauma Centre of India. Indian Journal of Surgery, 77, 530-535.

http://doi.org/10.1007/s12262-013-0908-2 
Singh, S., Remya, T., Shijo, M., \& Nair, P. (2014). Lean six sigma application in reducing nonproductive time in operation theaters. The Journal of National Accreditation Board for Hospitals \& Healthcare Providers, 1(1), 1. http://doi.org/10.4103/2348-6139.132908

Talati, S., Gupta, A., Kumar, A., Malhotra, S. K., \& Jain, A. (2015). An analysis of time utilization and cancellations of scheduled cases in the main operation theater complex of a tertiary care teaching institute of North India. Journal of Postgraduate Medicine, 61(1), 3-8. http://doi.org/10.4103/0022-3859.147009

Tolga Taner, M., Sezen, B., \& Antony, J. (2007). An overview of six sigma applications in healthcare industry. International Journal of Health Care Quality Assurance, 20(4), 329-340.

http://doi.org/10.1108/09526860710754398

Tolga Taner, M., Sezen, B., \& Atwat, K. M. (2012). Application of Six Sigma methodology to a diagnostic imaging process. International Journal of Health Care Quality Assurance, 25(4), 274-290.

http://doi.org/10.1108/09526861211221482

Vinukondaiah, K., Ananthakrishnan, N., \& Ravishankar, M. (2000). Audit of operation theatre utilization in general surgery. National Me 